\title{
Midwives' integration of post abortion manual vacuum aspiration in the Democratic Republic of Congo: a mixed methods case study \& positive deviance assessment
}

Kirsty M. Bourret ${ }^{1 *}$ (D), Sylvie Larocque ${ }^{2}$, Amélie Hien ${ }^{3}$, Carol Hogue ${ }^{4}$, Kalum Muray $^{2}$, Aurélie Thethe Lukusa ${ }^{5}$ and Abel Minani Ngabo ${ }^{6}$

\begin{abstract}
Background: Despite a recognized need for midwives to provide post abortion care, there exist barriers preventing them from integrating lifesaving skills such as manual vacuum aspiration (MVA) into practice. This collaborative research with the Professional Association of Congolese Midwives (SCOSAF), sought to understand how certain midwives in the Democratic Republic of Congo (DRC) have overcome barriers to successfully integrate MVA for post abortion care. Specifically, in order to provide locally-driven solutions to the problem of inadequate post abortion care in the DRC, this study aimed to identify examples of positive deviance, or midwives who had successfully integrated MVA in complex working environments following an in-service training facilitated by their midwifery association, SCOSAF.

Methods: Creswell's mixed method comparative case study design was used to identify positive deviant midwives who had practiced MVA one or more times post training and to explore their strategies and enabling factors. Other midwives who had not practiced MVA post training permitted for a comparison gro cup and further interpretations. Sources of data included a sequential survey and semi-structured interviews.

Results: All 102 midwives invited to be surveyed were recruited and 34\% reported practicing MVA post training (positive deviant midwives). No statistical significance was found between the two groups' demographics and practice facility type. Overall, both groups had positive attitudes regarding midwifery-led MVA and legalization of abortion. Positive deviant midwives demonstrated and described more confidence and competence to practice and teach MVA. They were more likely to identify as teachers and overcome interprofessional barriers by teaching MVA to physicians, medical students and other midwives and position themselves as experts during post abortion emergencies.

(Continued on next page)
\end{abstract}

\footnotetext{
* Correspondence: kx_bourret@laurentian.ca

${ }^{1}$ School of Midwifery, Faculty of Health Sciences, Laurentian University, 935

Ramsey Lake road, Sudbury, ON, Canada

Full list of author information is available at the end of the article
}

\section{$\triangle B M C$}

(c) The Author(s). 2020 Open Access This article is licensed under a Creative Commons Attribution 4.0 International License, which permits use, sharing, adaptation, distribution and reproduction in any medium or format, as long as you give appropriate credit to the original author(s) and the source, provide a link to the Creative Commons licence, and indicate if changes were made. The images or other third party material in this article are included in the article's Creative Commons licence, unless indicated otherwise in a credit line to the material. If material is not included in the article's Creative Commons licence and your intended use is not permitted by statutory regulation or exceeds the permitted use, you will need to obtain permission directly from the copyright holder. To view a copy of this licence, visit http://creativecommons.org/licenses/by/4.0/. The Creative Commons Public Domain Dedication waiver (http://creativecommons.org/publicdomain/zero/1.0/) applies to the data made available in this article, unless otherwise stated in a credit line to the data. 


\begin{abstract}
(Continued from previous page)
Conclusion: Results provided important insight to midwives' integration of post abortion care in Kinshasa. Strategies used by positive deviant midwives in emergencies allowed them to navigate challenging contexts in order to practice MVA, while simultaneously increasing the credibility of their profession and the dissemination of evidenced-based MVA practice. Programs designed to work with and promote positive deviant midwives as knowledge brokers could be tested for their overall impact on the diffusion of midwifery-led MVA to improve access to safe, respectful reproductive care.
\end{abstract}

Keywords: Democratic Republic of the Congo, Midwifery, Postabortion care, Abortion induced

\section{Background}

A critical need in many countries is adequate care arising from unsafe abortion practices. Restrictive abortion laws, conflict, displacement, lack of economic autonomy, war-based rape and violence, and legal and cultural restrictions contribute to women's high rates of unsafe abortions and related complications [1-4]. The maternal mortality rate in the Democratic Republic of Congo (DRC) is one of the highest in the world (846:100000) [5]; deaths due to illicit abortions contribute to at least $7 \%$ of all deaths $[5,6]$. In 2016, 40,090 women and girls obtained post abortion care with $77 \%$ requiring treatment for complications in the capital city of Kinshasa alone $[1,7]$. Mortality rates for post abortion complications are as high as $37.8 \%$ (95\% CI: $23.8-53.5 \%$ ) [8, 9] owing to critical gaps in community hospitals' provision of basic delivery services and few referral services for post abortion care $[6,7,10,11]$.

Deaths due to unsafe abortion could be reduced from 22,000 to 9000 [7] per year globally by meeting the need for post abortion care. Certain countries have endorsed the International Confederation of Midwives (ICM) policy on abortion provision $[12,13]$ by incorporating midwives into abortion-based strategies to reduce maternal mortality [14-19]. This innovative solution includes training midwives in the inexpensive and lifesaving procedure of manual vacuum aspiration (MVA). Countries such as the DRC have high maternal and neonatal mortalities, yet have an available, but under-utilized midwifery workforce [20-22]. Given the context and burden of illicit abortion in the DRC, with thousands of midwives available to be trained, there is great potential for a return on investment if midwives are properly supported in integrating MVA into their practice.

Currently, governmental policies and programs in the DRC have gaps regarding midwifery provision of post abortion care, but there are emerging efforts to address these issues $[10,20]$. The national professional midwifery association, SCOSAF (Société Congolaise de la Pratique Sage-Femme) is committed to strengthening its capacity to support members' integration of manual vacuum aspiration (MVA) into practice. In 2017, an emergency obstetric and neonatal skills (EmONC) continuing education program was created in a joint effort with the Ministry of Health resulting in over 350 midwives trained by SCOSAF in MVA for post abortion emergencies [23]. Post-training evaluations revealed limited integration of MVA overall [24]. However, anecdotally a small number of these trained midwives had found solutions to practicing MVA within challenging environments. To better understand how midwives had been successful, SCOSAF suggested approaching the research question of MVA integration from a solution-based lens. Positive deviance was thus selected as a methodology because its design was suitable for exploring how a small number of midwives had overcome barriers in order to practice MVA.

Contrary to a barrier-focused approach to health services research, positive deviance involves the identification of best practices within a community, resulting in better outcomes [25]. In other words, this approach examines how and why certain individuals have overcome barriers in order to provide local solutions to complex problems [26]. For example, in addressing the high rates of neonatal mortality, one rural community in Pakistan discovered that some midwives whose patients had low rates of neonatal death were naturally substituting old traditional birth practices by placing newborns skin-toskin following birth [26]. Following this discovery, those positive deviant midwives disseminated their knowledge to other midwives who then adopted the same practice [26]. Other examples include positive deviant nurses in Indonesia who displayed effective communication in family planning, and Rwandan adolescents who successfully negotiated condom use for HIV protection [26-30].

While positive deviancy has been used in similar contexts to explain better maternal health outcomes [31], this approach has not been used to study the integration of post abortion care practice by midwives. ${ }^{1}$ To date, scholarly work on this topic has been largely focused on a deficiencies approach to understand the organizational, technical and professional barriers that prevent MVA integration [17, 32-34]. There are therefore methodological gaps that address how midwives are strategizing

${ }^{1} \mathrm{KMB}$ consulted with a positive deviant researcher regarding research design. 
to overcome barriers to practice. This research aims to address these gaps in the context of midwifery in order to provide locally-driven solutions to the problem of inadequate post abortion care services in the DRC.

Our approach was to identify and examine "positive deviants" that is, those midwives who overcame barriers to providing post-abortion MVA. Particularly, we aimed to explore those strategies being successfully implemented and the role they had in fostering improvement, and to understand how they compare to midwives who had not yet integrated the skill. We developed the following research questions:

- Who are the positive deviant midwives who integrated MVA into practice post training?

- What strategies and factors facilitated adopting this skill?

- How do they compare to midwives who have not integrated MVA?

\section{Methods}

\section{Study design}

Positive deviant scholars recommend mixed-method design to identify and describe positive deviant individuals (10). Comparison to non-positive deviant individuals can aid in properly identifying behaviours and factors unique to positive deviants (44). Our research used Creswell's mixed method comparative case study design to address the research aims [25]. We identified positive deviant midwives who had initiated post abortion care (cases) and midwives who had not yet initiated post abortion care (comparatives) via a quantitative survey of midwives who had received training from their midwifery association (SCOSAF). We analyzed characteristics of each group for convergent or divergent factors [35]. Subsequently, we used a qualitative inquiry via semi-structured interviews with selected members in each case group to explore contextual factors and describe positive deviant behaviours used to achieve MVA integration. Data integration across methods then garnered an understanding of the characteristics of positive deviant individuals and their strategies [35]. Figure 1 shows the comparative case study approach used to identify positive deviant midwives and explore their strategies for MVA practice.

\section{Ethics approval}

Prior to data collection, we obtained ethics approval from the National Committee of Ethics of the Kinshasa School of Public Health in Kinshasa (\#ESP/CE/088/2019), Democratic Republic of Congo and the Research Ethics Board (\#6017245) at Laurentian University, Canada. Written informed consent was obtained from each participant.

\section{Population sampled}

Midwives considered eligible for the study had completed a 7-day emergency obstetric and neonatal care
*Trainings were conducted in Kinshasa DRC from September 2017 - March 2018

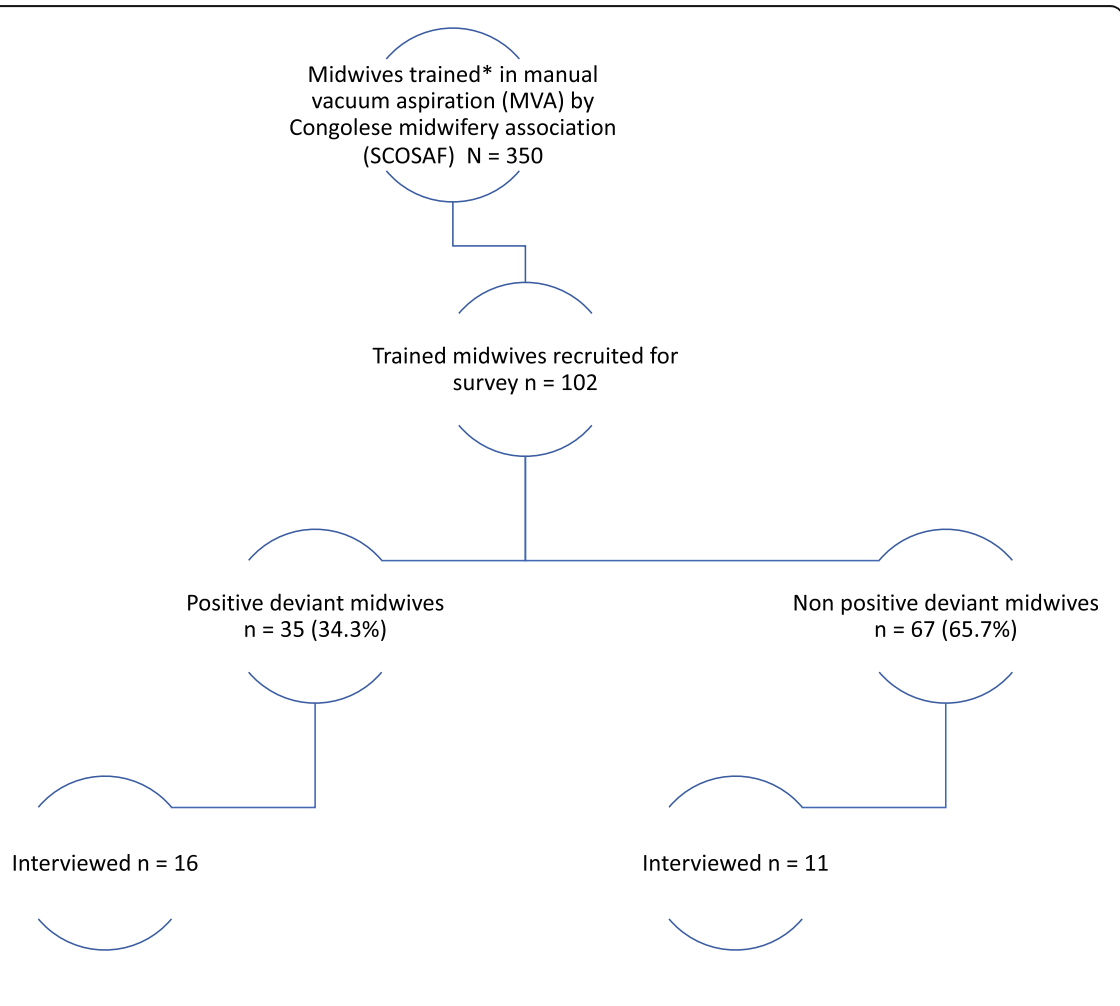

Fig. 1 Positive deviant research approach

Positive deviant $=$ having practiced MVA at least one time since training - Non positive deviant = having never practiced MVA since training 
(EmONC) training facilitated by SCOSAF between September 2017 to March 2018, during which 350 were trained from the nine major health zones in the province of Kinshasa. Trainees worked primarily in labour and delivery and varied in their work contexts and experience.

\section{Sample size}

Sample size of $5 \%$ prevalence of post-training MVA practice was based on previous post-training evaluations of Congolese midwives' report of frequent barriers to MVA integration [24], Previous studies provided little guidance for prevalence due to incomparable midwifery contexts [36]. The minimum sample size for a prevalence of 5\% with $95 \%$ confidence was 78 midwives. In the event that prevalence of MVA was lower than hypothesized we aimed for one-hundred midwives to be recruited for the survey.

\section{Case definition, sampling and recruitment}

The number of positive deviant midwives (cases) was hypothesized to be few. Therefore, the case group was bound by the deviant behaviour or outcome of practicing MVA for post abortion care one time or more since SCOSAF's training. The comparison group of nonpositive deviants was defined as midwives trained who had not practiced MVA for post abortion care since the training.

The design of our study required a multi-stage sampling approach for recruitment. We sequentially collected two sources of evidence between June 2019 and January 2020 to conduct the case group comparison. In stage one, to maximize the number of positive deviants, the local research team and KMB used the SCOSAF training database to create a list of all trained midwives working at health facilities offering MVA for post abortion care. The team took health facility characteristics into consideration to ensure diverse representation of working environments. ${ }^{2}$ All who were contacted by SCOSAF staff using a pre-approved script agreed to be surveyed. Recruitment ended when the desired sample size was met. Midwives no longer working at the time of recruitment were excluded. Participants were given a self-administered questionnaire that included questions about their post-training practice. Participants were divided into the two groups based on their answer to the question: "Have you ever provided MVA since the EmONC training?". In stage two, the local research team conducted semi-structured interviews of selected respondents from each case group. We recruited positive

\footnotetext{
${ }^{2}$ Hospitals were classified based on WHO signal functions to provide routine and emergency obstetric and neonatal care (EmONC) and their governing authority [37]
}

deviants to represent the range of MVA integration practices and comparators who best matched the demographics of the positive deviants (gender, age, years of practice).

We combined two context specific tools to create the survey for stage one of the research (Additional file 1). We first took questions from an EmONC training evaluation tool developed by SCOSAF and Ministry of Health in the DRC: "Expérience et confiance en compétences SONU" [38]. This tool had been used by the research team and participants in prior EmONC post training evaluations and included familiar and comprehensible terminology. Next, we included the IPAS "values clarification and attitudes transformation" survey, with permission, to measure the attitudes of midwives about providing post abortion care $[39,40]$. Together, this created a tool that provided data representing the range of factors proven to influence provider provision of post abortion care: socio-demographic characteristics, facility characteristics, provider training and experience, professional confidence, and personal attitudes and values towards abortion. The self-administered survey was in French (a national language) and was administered in a neutral setting, with local researchers available to provide additional explanations in the more common national language of Lingala. For stage two, the semistructured interview schedule explored barriers and facilitators to practice and how midwives were able to practice MVA (Additional file 2). Our local research team audio recorded the interviews and conducted them in a neutral setting in Lingala or French.

\section{Analytic strategy}

Both the positive deviant methodology and Rogers' Theory of Diffusions of Innovations Theory informed our analysis [26, 41]. The rationale for a positive deviant approach to MVA integration is that it aims to explain the actions of the few who, when faced with a problem or adversity, create solutions. Their solutions then can be organized and made accessible to the majority so they can have the tools needed to succeed [26, 42]. Success in confronting adversity depends in part on a combination of individual-, political-, health- and social-systems that positively or negatively impact an individual's or organization's ability to implement change [43]. Roger's Theory of Innovations provides a framework from which to analyze these complex factors and explain how positive deviant midwives have succeeded. Positive deviant applications of Rogers' theory represent a collaborative, community approach that can leverage local and feasible methods for disseminating innovations [44].

We used Rogers' three basic clusters of concepts as framework for the analysis and integration of data: 1) perceptions of the innovation; 2) characteristics of 
individuals who do or do not adopt the innovation; and 3 ) the context in which the innovation is introduced [45]. Within this framework, specific themes emerged from the data, reflecting both top down and bottom up approaches [25]. The intent of our study design was to integrate across methods and between cases in order to understand the characteristics of positive deviant individuals and identify their strategies [35]. Data analysis for each source of evidence occurred separately prior to the case group analysis and then were compared in the final interpretation (Fig. 2).

We descriptively summarized the survey responses from stage one for the overall sample of respondents. Participants' characteristics included socio demographics, professional experience, MVA practice, knowledge and attitudes regarding their role expansion and willingness to provide MVA for post abortion care. Questions regarding attitudes and values of MVA were measured using a Likert scale, which were added to create an overall score [39, 46]. Participants' MVA experience included observing or assisting in MVA procedures, perceived competence and confidence to practice and teach MVA, and perceived barriers and facilitators to practice. Their facility's characteristics included EmONC services provided, hospital governing authority, and facility supplies.

Using SPSS software, we conducted a bivariate analysis between case and comparator groups. We used chi-square tests for categorical variables. Due to non-normal distribution of attitudes and values about MVA, we analyzed for differences in the groups' scores using the non-parametric Mann Whitney-U test. Probabilities of less than 0.05 rejected the null hypothesis of no differences between the two groups.
Semi-structured interviews conducted in Lingala were forward translated to French and back translated by another researcher to ensure conceptual equivalence (AL, AM) [47]. Interviews conducted in French were transcribed directly and verified by the principal researcher (KMB). The interviews were uploaded in NVivo and a code structure was created using the three basic clusters of influence as outlined by Rogers's theory [45]. The first five transcripts were coded independently by $\mathrm{KMB}, \mathrm{AL}$ and $\mathrm{AM}$, and results were compared to ensure accuracy and to agree upon any new codes that emerged from the data. All discrepancies in the analysis were resolved together as a research team.

Data integration occurred at three points: The first point involved analysis of: 1) survey results between the groups of positive deviants and comparators; 2) qualitative findings from interviews between the two groups; and 3) a side-by-side comparison of results from both sources of evidence to locate convergences or divergences while exploring factors associated with positive deviant behavior. Second, integration occurred when results for each theme were compared between the groups. The third integration involved producing a narrative and joint display.

\section{Research collaboration regarding abortion}

In the DRC, abortion is legally restricted. As a result, clandestine abortions are common and stigmatized $[7,8]$. Our team gave strict attention to maintaining local collaboration, which is crucial in building trusting relationships and facilitating trustworthiness, particularly when researching topics that intersect with abortion [48]. This was achieved by creating a stakeholder committee

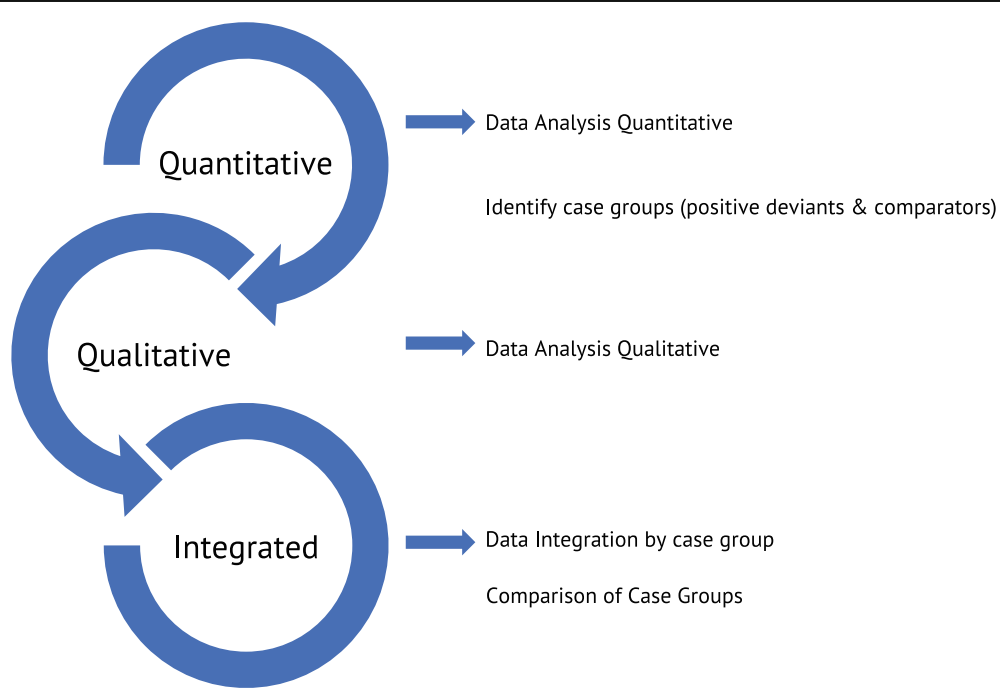

Fig. 2 Mixed methods case comparative research design 
Table 1 Characteristics of participants*

\begin{tabular}{|c|c|c|}
\hline & Survey Respondents $(n=102)$ & Interviewed $(n=27)$ \\
\hline Demographics of Participants & n $\left(\%{ }^{* *}\right)$ & n (\%) \\
\hline \multicolumn{3}{|l|}{ Gender } \\
\hline Male & $9(8.8)$ & $4(14.8)$ \\
\hline Female & $93(92.2)$ & $23(85.2)$ \\
\hline \multicolumn{3}{|l|}{ Age } \\
\hline 20-39years & $40(40.8)$ & $9(33.3)$ \\
\hline 40-59 years & $58(59.2)$ & $18(66.6)$ \\
\hline \multicolumn{3}{|l|}{ Years as midwife } \\
\hline 15 years and less & $24(24.2)$ & $16(59.3)$ \\
\hline More than 15 years & $75(75.8)$ & $11(40.7)$ \\
\hline \multicolumn{3}{|l|}{ Type of Midwife } \\
\hline Midwife & $65(63.7)$ & $18(66.7)$ \\
\hline Auxiliary midwife & $37(36.2)$ & $9(33.3)$ \\
\hline Teaching (official or otherwise) & $27(26.5)$ & $8(29.6)$ \\
\hline Other MVA training & $25(25.3)$ & $9(33.3)$ \\
\hline Other EmONC training & $29(28.7)$ & $8(29.6)$ \\
\hline \multicolumn{3}{|l|}{ Hospital Characteristics } \\
\hline \multicolumn{3}{|l|}{ Type of EmONC services } \\
\hline Comprehensive & $86(85.1)$ & $24(88.9)$ \\
\hline Basic & $15(14.9)$ & $3(11.1)$ \\
\hline \multicolumn{3}{|l|}{ Operating Authority } \\
\hline Government & $86(84.3)$ & $17(63)$ \\
\hline Private & $9(8.8)$ & $5(18.5)$ \\
\hline Catholic (Mission) & $7(6.9)$ & $5(18.5)$ \\
\hline Offers MVA for post abortion care & $91(90.1)$ & $24(88.9)$ \\
\hline Consistent supplies MVA & $65(63.7)$ & $21(77.8)$ \\
\hline
\end{tabular}

*The sample was chosen from a purposive list of 350 midwives trained by SCOSAF in MVA in either 2017 or 2018, working in facilities offering MVA for post abortion care. All midwives contacted to participate in the study agreed to be surveyed

**Percentages among known responses

comprised of governmental and non-governmental experts in midwifery and abortion care and with a team of two Congolese midwife researchers. ${ }^{3}$

As midwives belonging to the midwifery association, the team of researchers held a unique and important insider perspective regarding the provision of post abortion care, and a high degree of cultural sensitivity and understanding in relation to the research topic (37). Cultural competence is known to increase the researcher's ability to properly represent reality and foster trust with

\footnotetext{
${ }^{3}$ The stakeholder committee comprised of governmental and nongovernmental experts in midwifery and abortion care including SCOSAF, PNSR (programme national de la santé reproductive), SCOGO (Société Congolaise de Gynécologie et d'Obstétrique), UNFPA (United Nations Population Fund) and IPAS (International NGO for reproductive rights and health). This committee provided guidance at various points during the research process, including local ethics approval, research design, data collection instruments, data analysis and results.
}

participants in abortion research contexts [49]. Further, culturally competent researchers can self-reflect and recognize their own biases [49]. We therefore considered this insider perspective as contributory to the trustworthiness of the research. An outside researcher might cause discomfort to the participants and create an environment where they felt intimidated and judged.

\section{Results}

Characteristics of participants

1. A total of one hundred and two $(n=102)$ midwives participated in the study. The social, demographical and professional characteristics of the participants and subset are presented in Table 1. Thirty-five (35) of the 102 participants had practiced MVA since being trained (34.3\%). Of those midwives 21 (20.6\%) applied it for the first time, and 14 (13.7\%) had improved their technique since the training. Prevalence is presented in Table 2 
Table 2 Variations of MVA practice

\begin{tabular}{lll}
\hline & Survey Respondents $(\boldsymbol{n = 1 0 2})$ & Interviewed $(\boldsymbol{n}=\mathbf{2 7})$ \\
\hline Prevalence of MVA & $\mathbf{n}(\%)$ & $\mathbf{n}(\%)$ \\
1st time since MVA training & $21(20.6)$ & $7(25.9)$ \\
Better since MVA training & $14(13.7)$ & $9(33.3)$ \\
Never & $67(65.7)$ & $11(40.7)$ \\
Frequency of MVA practice & & \\
One time ever & $17(16.7)$ & $8(29.6)$ \\
Every 6 months & $6(5.9)$ & $2(7.4)$ \\
Every month & $12(11.8)$ & $6(22.2)$ \\
n/a & $67(65.7)$ & $11(40.7)$
\end{tabular}

and all bivariate associations of the two case groups are presented in Table 3.

\section{Case study results}

A subset of twenty-seven (27) participants were interviewed. We reached saturation with 16 positive deviants and 11 comparators. No potential positive deviants refused to be interviewed, but 11 comparators selected for interviews could not be reached due to changes in contact information. All comparators reached agreed to participate. Table 4 presents a joint display of qualitative and quantitative results across groups, with data organized into the three themes derived from observations based on the original framework:

2.1) Midwifery perceptions of MVA, abortion and midwifery scope of practice, 2.2) Midwives' confidence and competence of MVA, and, 2.3) Immediate working context. Each category was further divided into subthemes. The following narrative is an interpretation of data integration and a comparison of positive and nonpositive deviant midwives by categoric theme. Divergences and convergences are additionally explored.

\section{Perceptions of MVA}

\section{Midwifery scope and MVA}

In the survey, groups demonstrated equivalent knowledge of the midwifery scope of practice in the DRC $(p=0.164)$. The interviews revealed similar changes across groups in perspective and knowledge of midwives' role with regards to post abortion care from SCOSAF's MVA training. Specifically, they expressed the opinion that midwives' involvement in MVA practice increased the credibility of their profession and is an essential skill, as midwives are well positioned and capable of saving the lives of women who had undergone clandestine abortions.

In relation to their ability to integrate MVA, positive deviants described how SCOSAF's training allowed them to fully understand their autonomy and the key role they hold within the health care system to decrease maternal mortality due to unsafe abortions. This newfound empowerment and self-perception as an MVA provider were catalysts to practice and evolved their own professional identity in favour of practicing MVA:

Previously, this practice in our structure was reserved only for doctors (...). When we followed the training and especially when we had just learned that MVA is part of the field of midwifery practice, (..) since then I work in collaboration with the doctors when it comes to the use of $M V A^{4}$ (case group 1: participant 1).

Positive deviants also associated their practice of MVA with its overall positive impact on midwifery by increasing midwives' credibility with colleagues and clients. They saw MVA practice as honourable and important for midwifery and the advancement of maternal and child health. Indeed, this new sense of autonomy and credibility allowed them to advance their own position as midwives within their hospitals, often evolving into leadership roles and propagating the use of MVA:

It gave me value and consideration in the eyes of others...I am happy to be the champion and leader in my structure, because it is thanks to me that everyone practices MVA (case group 1: participant \#14).

Comparators had similar knowledge and views of MVA within their scope of practice. In interviews they revealed no negative opinions or views regarding MVA being within the scope of midwifery practice for post abortion care. However, they did not apply this to their own personal practice or lack thereof:

It is really very important that the midwife performs MVA to save the lives of women who die every day

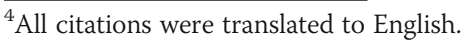


Table 3 Bivariate associations between positive deviants and comparators

\begin{tabular}{|c|c|c|c|}
\hline & Positive Deviant Midwives $(n=35)$ & Non-Positive Deviant Midwives $(n=67)$ & \\
\hline & n (\%) & n (\%) & $p$ value \\
\hline \multicolumn{4}{|l|}{ Demographics } \\
\hline \multicolumn{4}{|l|}{ Age } \\
\hline 20-39 years & $11(33.3)$ & $20(30.8)$ & 0.80 \\
\hline $40-59$ years & $22(66.7)$ & $45(69.2)$ & \\
\hline \multicolumn{4}{|l|}{ Years as midwife } \\
\hline 15 years and less & $21(61.8)$ & $42(64.6)$ & 0.78 \\
\hline More than 15 years & $13(38.2)$ & $23(35.4)$ & \\
\hline \multicolumn{4}{|l|}{ Type of Midwife } \\
\hline Midwife & $23(65.7)$ & $42(62.7)$ & 0.76 \\
\hline Auxiliary midwife & $12(34.2)$ & $25(37.3)$ & \\
\hline \multicolumn{4}{|l|}{ Professional Experience } \\
\hline Teaching (official or otherwise) & $16(45.7)$ & $11(16.7)$ & $0.002^{*}$ \\
\hline \multicolumn{4}{|l|}{ Year trained in EmONC } \\
\hline 2017 & $17(48.6)$ & $23(36.5)$ & 0.24 \\
\hline 2018 & $18(51.4)$ & $40(63.5)$ & \\
\hline Teaching (official or otherwiseOther MVA training & $15(44.1)$ & $10(15.4)$ & $0.002^{*}$ \\
\hline Other EmONC training & $13(37.1)$ & $16(24.2)$ & 0.17 \\
\hline \multicolumn{4}{|l|}{ Additional MVA experience } \\
\hline Observed 1st since training & $11(31.4)$ & $21(31.3)$ & 0.99 \\
\hline Observed prior training & $6(17.1)$ & $12(17.9)$ & 0.92 \\
\hline Assisted 1st since training & $9(25.7)$ & $17(25.4)$ & 0.97 \\
\hline Assisted prior training & $14(40.0)$ & $11(16.4)$ & $0.009^{*}$ \\
\hline \multicolumn{4}{|l|}{ MVA for therapeutic abortion } \\
\hline Yes & $12(34.3)$ & $3(4.6)$ & $<0.0005^{* *}$ \\
\hline Not comfortable answering & $7(20.0)$ & $17(26.2)$ & \\
\hline \multicolumn{4}{|l|}{ Confidence } \\
\hline \multicolumn{4}{|l|}{ Level of confidence to practice MVA } \\
\hline Very confident to practice & $24(68.6)$ & $10(17.9)$ & $<0.0005^{*}$ \\
\hline Not very confident & $11(31.4)$ & $46(82.1)$ & \\
\hline Perceived competence to practice MVA & $31(91.2)$ & $39(59.1)$ & $0.001^{*}$ \\
\hline \multicolumn{4}{|l|}{ Barriers and facilitators } \\
\hline \multicolumn{4}{|l|}{ Barriers } \\
\hline Lack of interprofessional support & $9(25.7)$ & $11(16.4)$ & 0.26 \\
\hline Lack of MVA supplies & $11(31.4)$ & $38(56.7)$ & $0.02^{*}$ \\
\hline Lack of MVA aspirator & $11(31.4)$ & $32(47.8)$ & 0.11 \\
\hline \multicolumn{4}{|l|}{ Facilitators } \\
\hline SCOSAF & $32(91.4)$ & $46(68.7)$ & $0.01^{*}$ \\
\hline \multicolumn{4}{|l|}{ Ancillary support to practice } \\
\hline Mentorship & $14(40)$ & $32(47.8)$ & 0.46 \\
\hline MVA equipment & $17(48.6)$ & $41(61.2)$ & 0.22 \\
\hline \multicolumn{4}{|l|}{ Facility characteristics } \\
\hline \multicolumn{4}{|l|}{ EmONC services } \\
\hline Comprehensive & $29(82.9)$ & $57(86.4)$ & 0.64 \\
\hline
\end{tabular}


Table 3 Bivariate associations between positive deviants and comparators (Continued)

\begin{tabular}{|c|c|c|c|}
\hline & Positive Deviant Midwives $(n=35)$ & Non-Positive Deviant Midwives $(n=67)$ & \\
\hline & n (\%) & n (\%) & $p$ value \\
\hline Basic & $6(17.1)$ & $9(13.6)$ & \\
\hline \multicolumn{4}{|l|}{ Operating Authority } \\
\hline Government & $27(77.1)$ & $59(88.1)$ & 0.15 \\
\hline Private/Mission & $8(22.9)$ & $8(11.9)$ & \\
\hline Consistent supplies for MVA & $27(77.1)$ & $38(56.7)$ & $0.04^{*}$ \\
\hline
\end{tabular}

*factors not included if cell size was smaller than 5 units

*significant if $p<0.05$

as a result of abortions... it should also be noted that MVA is part of the scope of midwifery in the DRC

(Case group 2: Participant 25).

\section{Attitudes about post abortion care}

Overall, midwives expressed positive attitudes and professional intent to practice post abortion care. In the survey, midwives scored similarly to questions regarding their willingness to provide post abortion care, to be publicly known as a post abortion provider, and their beliefs of abortion legislation. Mean scores were high at $86.91 \%$ (mean S.E. 1.18) for positive deviants and $85.18 \%$ (mean S.E. 1.52) for comparators, with no statistical difference between the rank mean scores $(p=0.92)$. During interviews, both groups acknowledged the rate of unwanted pregnancies as too high in their country, contributing to higher levels of deaths due to clandestine abortions. They expressed belief that midwives must address this problem by advocating for better access to contraception, decreasing illegal activities and improving

Table $\mathbf{4}$ Thematic case groups comparisons (see legend)

\begin{tabular}{|c|c|c|c|c|}
\hline DOMAIN & \multicolumn{2}{|c|}{ POSITIVE DEVIANT MIDWIVES } & \multicolumn{2}{|c|}{ NON-POSITIVE DEVIANT MIDWIVES } \\
\hline \multirow{4}{*}{$\begin{array}{c}\text { PERCEPTIONS } \\
\text { OF MIDWIVES \& } \\
\text { MVA }\end{array}$} & \multicolumn{2}{|c|}{ MVA in my scope permits me to practice MVA and increases my professional credibility } & \multicolumn{2}{|c|}{ MVA is in midwifery scope of practice and is very important to their professional credibility } \\
\hline & \begin{tabular}{|c|} 
When we followed the training and especially when we had just \\
learned that $M V A$ is part of the midwifery scope of practice (...) \\
since then, I have been working in collaboration with doctors \\
when it comes to the use of $M V A$.
\end{tabular} & \multicolumn{2}{|c|}{ Equivalent knowledge of the midwifery scope of practice in the DRC $(p=0.164)$} & $\begin{array}{l}\text { It is really very important that the midwife practices } M V A \text { to } \\
\text { save women's lives (...) it should also be noted that } M V A \text { is } \\
\text { part of our scope of practice in the DRC. }\end{array}$ \\
\hline & \multicolumn{4}{|c|}{ The midwifery profession has an important role to play in sexual and reproductive health and rights specifically in the reduction of deaths due to illegal abortion } \\
\hline & $\begin{array}{l}\text { The role of the midwife is to sensitize the population on family } \\
\text { planning and to advocate for the legalization of abortion. }\end{array}$ & $\begin{array}{l}\text { Equivalent rank mean scores of attitudes } \\
\qquad 85.18 \% \text { mean } \mathrm{S} .\end{array}$ & $\begin{array}{l}\text { and values }(86.91 \% \text { mean S.E. } 1.18 \mathrm{vs} \\
\text { E. } 1.52 \mathrm{p}=0.92)\end{array}$ & $\begin{array}{l}\text { Our role is to reduce maternal mortality, so we have a vested } \\
\text { interest in educating women and (...)we must perform MVA } \\
\text { and not let that woman die. }\end{array}$ \\
\hline \multirow{6}{*}{$\begin{array}{l}\text { CONFIDENCE } \\
\text { TO PRACTICE }\end{array}$} & \multicolumn{2}{|c|}{ Training and teaching impact my confidence to practice MVA } & \multirow[t]{2}{*}{ Training impact my confidence } & e somewhat, but I need further support to pratice \\
\hline & \begin{tabular}{|c|} 
The things that impact my confidence in MVA are the exercises \\
we did several times in training; and I practiced a few times with \\
our syringe; and I felt confident applying the technique for a \\
client.
\end{tabular} & $\begin{array}{l}\text { Very confident versus somewhat confid } \\
\text { Identifies as a teacher }(\mathrm{p}=0.002)\end{array}$ & & $\begin{array}{l}\text { The factors that influence my confidence is the training and } \\
\text { the fact that I often assist. I am more and more confident, but } \\
\text { I still need to be supported when I do it for the first time. }\end{array}$ \\
\hline & \multicolumn{2}{|c|}{ I am motivated and have courage to practice MVA } & \multicolumn{2}{|c|}{ I am not personally motivated to practice MVA } \\
\hline & \multicolumn{2}{|c|}{ The elements that influence my confidence to practice MVA are (...) also my courage and determination. } & \multicolumn{2}{|c|}{$\begin{array}{l}\text { We have already integrated MVA at our hospital, but the thing that inhibits me is the lack of } \\
\text { determination on my part. }\end{array}$} \\
\hline & \multicolumn{2}{|c|}{ I feel competent to practice MVA due to my training and exposure } & \multicolumn{2}{|c|}{ I need more exposure in order to feel competent to practice MVA } \\
\hline & $\begin{array}{c}\text { Yes, I have already practiced MVA just once, (...) we went } \\
\text { through the SONU training as well as the high frequency small } \\
\text { dose training. }\end{array}$ & \multicolumn{2}{|c|}{$\begin{array}{l}\text { SCOSAF support for successful integration }(\mathrm{p}=0.010) \\
\text { Self perceived competence following SCOSAF training ( } \mathrm{p}=0.001) \\
\text { Received complementary MVA training ( } \mathrm{p}=0.002) \\
\text { Previously assisted with MVA procedures prior to their training ( } \mathrm{p}=0.009)\end{array}$} & $\begin{array}{l}\text { I don't think if I have a woman in front of me with an } \\
\text { incomplete abortion that I can apply MVA; I still need } \\
\text { coaching before I can do it. }\end{array}$ \\
\hline \multirow{6}{*}{ CONTEXT } & \multicolumn{2}{|c|}{ I have to secure my own MVA to ensure I can practice } & \multicolumn{2}{|c|}{ Materials are present in my institution and other midwives practice MVA } \\
\hline & $\begin{array}{c}\text { The presence of the syringe also in our structure helped a lot, } \\
\text { because even if you know the technique, but if you don't have the } \\
\text { materials it's difficult. }\end{array}$ & \multicolumn{2}{|c|}{ Access to MVA equipment was statistically significant to practice $(p=0.042)$} & Often we work together and we have the right equipment. \\
\hline & \multicolumn{2}{|c|}{ Doctors support me to provide MVA } & \multicolumn{2}{|c|}{ Doctors support my colleagues to practice MVA } \\
\hline & $\begin{array}{c}\text { The doctor on duty did not have a very good grasp of the } \\
\text { technique, so I suggested if I could perform MVA (...) The doctor } \\
\text { and my team trusted me and they assisted me, from start to } \\
\text { finish. }\end{array}$ & \multicolumn{2}{|c|}{ No significance between support from colleagues and MVA practice $(\mathrm{p}=0.262)$} & $\begin{array}{l}\text { Yes, in our maternity ward, the majority of the midwives were } \\
\text { trained in EmONC and MVA and they practice together with } \\
\text { the doctors. }\end{array}$ \\
\hline & \multicolumn{2}{|c|}{ Professional competing interests impact midwives ability to practice MVA } & \multicolumn{2}{|c|}{ Professional competing interests impact midwives ability to practice MVA } \\
\hline & \multicolumn{2}{|c|}{$\begin{array}{l}\begin{array}{c}\text { There are some doctors who are jealous and think that } M V A \text { is an act reserved only for doctors, because } \\
\text { for each act there is a percentage that goes into the doctor's fee, so if they let me do it every time, it's a loss } \\
\text { of income for them. }\end{array} \\
\end{array}$} & \multicolumn{2}{|c|}{$\begin{array}{l}\text { The factors that inhibit me are the lack of support from my colleagues because the materials are there } \\
\qquad \text { and I often assist them. }\end{array}$} \\
\hline \multicolumn{5}{|c|}{ Legend } \\
\hline \multicolumn{5}{|c|}{ Case groups converge } \\
\hline \multicolumn{5}{|c|}{ Case groups diverge } \\
\hline
\end{tabular}


abortion laws. Both groups spoke of inequities in their health care systems that lead to unsafe abortions, that the system was unfair and had a negative impact on women and girls.

I think that many girls or young people resort to clandestine abortions because the Ministry of Health has not set up a safe abortion process, many women do these abortions because their pregnancies are unwanted (case group 1: participant 1).

Midwives discussed the importance of improving their country's policies and programs to improve access to birth control and abortion and were clear that midwifery needs to be present at all levels of implementation:

Midwives have a very crucial role to play in raising women's awareness on family planning but also, we have to advocate for the correct application of the Maputo Protocol, and also participate in decision making regarding women's health. (case group 2: participant 25).

\section{Midwives' confidence and competence of MVA Confidence}

In the survey, midwives were asked to rank their confidence to practice and teach MVA post training. Positive deviants were more likely than comparators to report being very confident, while comparators were more likely to be somewhat confident to practice MVA $(p<0.0005)$. Positive deviants were more likely than comparators to hold a formal or informal teaching role $(p=0.002)$. They were also more likely to express confidence in their ability to teach MVA (64.2\% compared with $94.3 \%$ of comparators expressing only somewhat confidence to teach MVA).

In the interviews, midwives were asked to describe their levels of confidence including what factors impacted their confidence to practice MVA. Positive deviants used words such as self-worth, personal conviction, motivation and courage to describe the internal or inherent factors that increased their confidence to practice, particularly with regards to the first time they practiced MVA.

My experience for the integration of MVA is only the fruit of my conviction and my courage, a case arrived and the emergency doctor didn't know what to do and he left me in charge (case group 1: participant 2).

Midwives described that successfully performing MVA for the first time under extremely stressful conditions reinforced their confidence by positively impacting their self-respect, self-worth and perceived place within their interdisciplinary team. This new confidence as a team member led them to share their knowledge by teaching and training others to use MVA. Being a teaching resource or reference point in their hospital also positively impacted their confidence as practitioners.

\section{My level of confidence is stable because I master the technique perfectly and I also train others (...) I have even become a leader in my structure (case group1: participant 6).}

Conversely, comparators described an inherent lack of motivation or interest to practice MVA or to ask someone to mentor them. Midwives suggested that it was purely a matter of self-determination and a personal decision to motivate themselves to practice or to ask for help:

I think I've mastered the technique with what I see from my colleagues. But I just lack determination and a little bit of decisiveness because I wasn't interested in it at all (case group 2: participant 19).

Some described that their confidence to practice was poor due to the length of time since their training, or lack of exposure in clinical practice. This led to needing more mentorship or supervision, or even more training so they could be confident enough to practice:

The element that impact my confidence is the lack of practice after the training because if you have learned something and you don't practice, you forget certain steps, but I would need someone to assist me the day I do the MVA (case group 2: participant 22).

Many comparators were working in contexts where MVA was practiced by either physicians or other midwives. They seemed to be content to support their colleagues in MVA procedures instead of performing MVA themselves. However, if faced alone with a clinical situation that demanded MVA, they often described full intent to provide the necessary care, regardless of their confidence levels:

Yes, I would like to practice MVA 1 day and I know that 1 day I will do it because with the EmONC training and as I already assist those who do it if a case happens and I am alone I will do it. (case group 2: participant 18).

\section{Confidence and competence}

The most common external factor that influenced midwives' confidence to practice MVA was their SCOSAF 
training. In the survey, positive deviants were more likely than comparators to report they felt competent following the training $(p=0.001)$. They were also more likely to identify SCOSAF as the primary source of support for successful integration $(p=0.010)$. In the interviews, both groups discussed the importance of receiving MVA training from SCOSAF and its positive impact on their competence. Discussions differed between the groups based on how much the training and perceived competency impacted their confidence to actually practice on their own. The comparators expressed more reticence towards practicing and discussed needing ancillary supports before they felt completely confident:

The factor that impacts my confidence is the EmONC training (...) but I still need to be supported by the experts when I do it for the first time (box group2: participant 20).

However, perceived competence achieved from the training to practice MVA did impact positive deviants' practice, compelling them to apply their knowledge:

The elements that impact my confidence in MVA are the exercises that we did several times at the training; and when I came home, I practiced a few times with our syringe; and I felt confident applying the technique to a client (case group 1: participant 1).

In the survey, length of time since being trained (2017 or 2018) was not associated with whether midwives had initiated MVA practice $(p=0.24)$, however interviews with comparators revealed that their confidence had waned over time:

At the moment my confidence level is a bit low (...) which means that for the moment before practicing I first have to redo the theoretical and practical training we received at SCOSAF (case group 2: participant 23).

Another influence appeared to be the amount of training and experience midwives had had prior to the training. The survey revealed that positive deviants were more likely than comparators to have previously assisted with MVA procedures prior to their training $(p=0.009)$ and to have received complementary MVA training $(p \leq$ 0.002).

\section{Context}

Results for context are divided into two categories addressing: 1) the midwives' immediate work environments such as supply and equipment and 2) working relationships, particularly in the working environment at the actual moment of the emergency or MVA practice.

\section{Access to MVA equipment}

MVA integration did not differ whether midwives were working for public or private entities nor if their hospital provided basic or comprehensive EmONC care. During the interviews, several participants referred to their hospital-specific training which had left mannequins for training and equipment at their disposal.

Having immediate access to MVA equipment was statistically associated with practice $(p=0.042)$. MVA equipment was either made available by the hospital, which in many cases was due to the donations of an organization, belonging to a medical colleague, or the midwife themselves. Midwives described MVA availability as inconsistent, caused by stock outages or doctors taking the equipment home with them. This midwife described how she stowed her own MVA to guarantee consistent access in emergencies:

Then we brought her to my office and as all the materials are in there, I suctioned out the contents and in a few minutes the woman was saved (case group 1: participant 6).

\section{Relationships and access to MVA}

While the survey found no significance between support from colleagues and MVA practice $(p=0.26)$, both groups discussed the importance of care provider relationships throughout the interviews. Predominantly, midwives discussed who was present or not during emergencies making clear that the interprofessional encounter was more relevant than overall institutional environment. Interprofessional relationships were most often with physicians followed by medical students or midwives.

Positive deviants in the private sector revealed competing financial interests between themselves and physicians. More complicated procedures, such as dilatation and curettage, cost more for a patient and therefore, were more profitable for physicians. When physicians were present, midwives were less likely to manage the client's care. MVA profits also caused interprofessional tensions, resulting in a reluctance on the part of some physicians to allow midwives to perform post abortion care.

There are some doctors who are jealous and think that MVA is a procedure reserved only for doctors, because for each procedure there is a percentage that goes into the doctor's fee; so, if they let me do it every time, it's a loss of income for them (case group 1: participant 1). 
For comparators, competing interests between physicians and midwives and their own motivation to practice were described simultaneously. While they expressed a desire for more support from their peers, they often stated that midwives and physicians were already practicing in their setting. They described both a need for their peers to be more inclusive of them, while admitting they could also be more confident and motivated to include themselves:

The factors that inhibit me are the lack of support from my colleagues because the materials are there and I often assist them, but I think that I too must have the courage (case group 2: participant 18).

Many comparators discussed collaborations with their peers in order to assist them during emergencies and described a sense of accomplishment in these collaborations in order to save a life:

the woman was bleeding so badly that we couldn't wait many minutes because her life was in danger. I and the other midwife had decided to do the MVA (...), and we aspirated (...) I actively assisted and we were able to save that woman's life (case group 2: participant 26).

Positive deviants also described their interactions with physicians during emergencies as educational encounters. If the physician did not know the technique, the midwife would capitalize on the occasion to inform and teach. Midwives discussed how they were in many cases able to convince their peers of the benefits of MVA during the emergency:

The doctor who was there asked that we could prepare the material for the curettage, as I had just been trained and we still had the MVA syringe that had never been used; I proposed to the doctor that we could first try the new aspiration technique; after my explanations on the advantages of the technique, they accepted and I did so in front of the doctor and my colleagues who also learned that day (case group 1: participant 14).

The doctor on duty did not have much knowledge of the technique, so I suggested if I could perform MVA. The doctor and my team trusted me and assisted me from start to finish (case group 1: participant 15).

Teaching during one emergency could lead to the midwife teaching others as other emergencies arose:
I did it 1 day in an emergency and the doctor was busy, and we saved this woman together with the trainee doctor...I master the technique well and I can do it alone without supervision and I teach the other doctors to do it (case group 1: participant 5).

\section{Discussion}

Our research found that positive deviants encompassed all ages, types of midwives, experience levels and facilities. While their perceptions of the scope of midwifery and MVA for post abortion care differed little from comparators, one distinction is clear. In an emergency, positive deviants relied on their self-confidence fueled by motivation, sense of professional credibility and competence. In each story, positive deviants described an emergency that became a critical juncture leading them to initiate MVA. With MVA equipment at hand and the right combination of inter- or intra-professional support, those midwives were able to push past institutional and cultural norms regarding their role in post abortion emergencies. Faced with a clinical emergency, this combination of internal and external factors propelled them to courageously apply the MVA technique.

Positive deviants further leveraged their confidence as MVA practitioners and as teachers in order to inspire their colleagues to trust in their expertise and to learn the MVA technique from them. Examples included convincing colleagues to abandon dilatation and curettage, a riskier yet commonly practiced skill, and teaching the MVA technique to physicians and residents. This strategy of positioning themselves as mentors in an emergency allowed them to momentarily transcend the traditional patriarchal structures of their institution and health system. This non-threatening approach was acceptable to their physician colleagues in the moment. Following this event, midwives evolved into a mentor and in some cases an expert in their institution.

Our findings are similar to a study of integrating MVA for post abortion care in Ghana. Post training, investigators reported a similar prevalence $(31 \% p=0.015)$ [36]. In that study, working in private facilities was the only association across midwife characteristics and MVA practice. The prevalence of midwifery MVA integration was lower than among physician participants (80\%), which authors attributed to organizational and professional barriers. Mistrust of midwives and lack of clear definition of the midwifery model of care also contribute to the midwife's difficulty practicing the new skill [33, 50].

Our qualitative results mirror a systematic review regarding task shifting in midwifery, where sharing a skill across traditional professional boundaries challenged hierarchical structures [33, 50]. Abortion is typically a medical act. Dilatation and curettage was historically the 
preferred method for post abortion care, and is a highly medicalized event [51]. MVA is a newer, simpler, safer and less technical skill [51] that can be conducted by midwives, in all facilities that offer birth [51]. As the skill is proven to be less technical, it therefore becomes unjustifiable to withhold its use from midwives, yet there remains a real medical resistance and mistrust of midwives' capacity to manage abortion care $[19,52]$. In a survey of midwives at an international midwifery congress $41 \%$ of midwives qualified to provide MVA reported that they were prevented from practicing, listing medical professional and organizational structures as barriers [32].

While our research found that physician support and trust were conducive to midwifery practice across both positive deviant and comparator groups, our research adds an important insight to explain how midwives navigated challenging professional boundaries and in doing so, increased the trust and corroboration of their medical peers. Similar to some previous studies, confidence is an important starting point $[34,53]$. However, we also found that confidence was enhanced by positive deviants' motivation and interest in practicing MVA, leveraged by their strong sense of professional identify and scope of practice and their perceived competence and knowledge of the skill. Comparators were less confident and motivated to practice, while still remaining supportive.

Our research provides further insight into how midwives trained in MVA challenged and overcame interprofessional barriers by strategically positioning themselves in a clinically urgent situation, making a calculated risk to save a life. Positive deviants presented themselves as intermediaries or knowledge brokers, promoting the practice of MVA to their peers, a still uncommon practice in their context, while subtly demonstrating the role of the midwife in a post abortion emergency. Figure 3 represents a proposed framework explaining how positive deviants challenged professional boundaries, integrated MVA and increased the trust of their medical peers. Knowledge brokers in similar contexts to the DRC have been shown to successfully disseminate information based on their ability to actively seek opportunities to demonstrate evidence-based practice, network and build relationships, and adapt to the immediate context [54]. Like knowledge brokers, positive deviants were driven by their internal motivation and beliefs of midwifery and sexual and reproductive rights. They had the confidence to creatively adapt in an emergency and to act quickly in a non-threatening manner, overcoming professional and gendered norms while simultaneously raising awareness and credibility of the midwifery profession.

\section{Strengths and limitations}

Three main strengths of this study include: 1 ) the mixed method case study design that allowed for an in-depth analysis of the "who" and "how" Congolese midwives integrate MVA into practice; 2) the positive deviant approach that allowed for identifying pragmatic solutions that overcome well documented professional barriers to MVA integration; and 3) the collaborative approach that provided SCOSAF with vital information to leverage midwifery in the context of abortion care in their country.

The main limitation of the study was due to the coronavirus pandemic. Travel and ethical restrictions meant a required adaptation to the final step of study. Rather

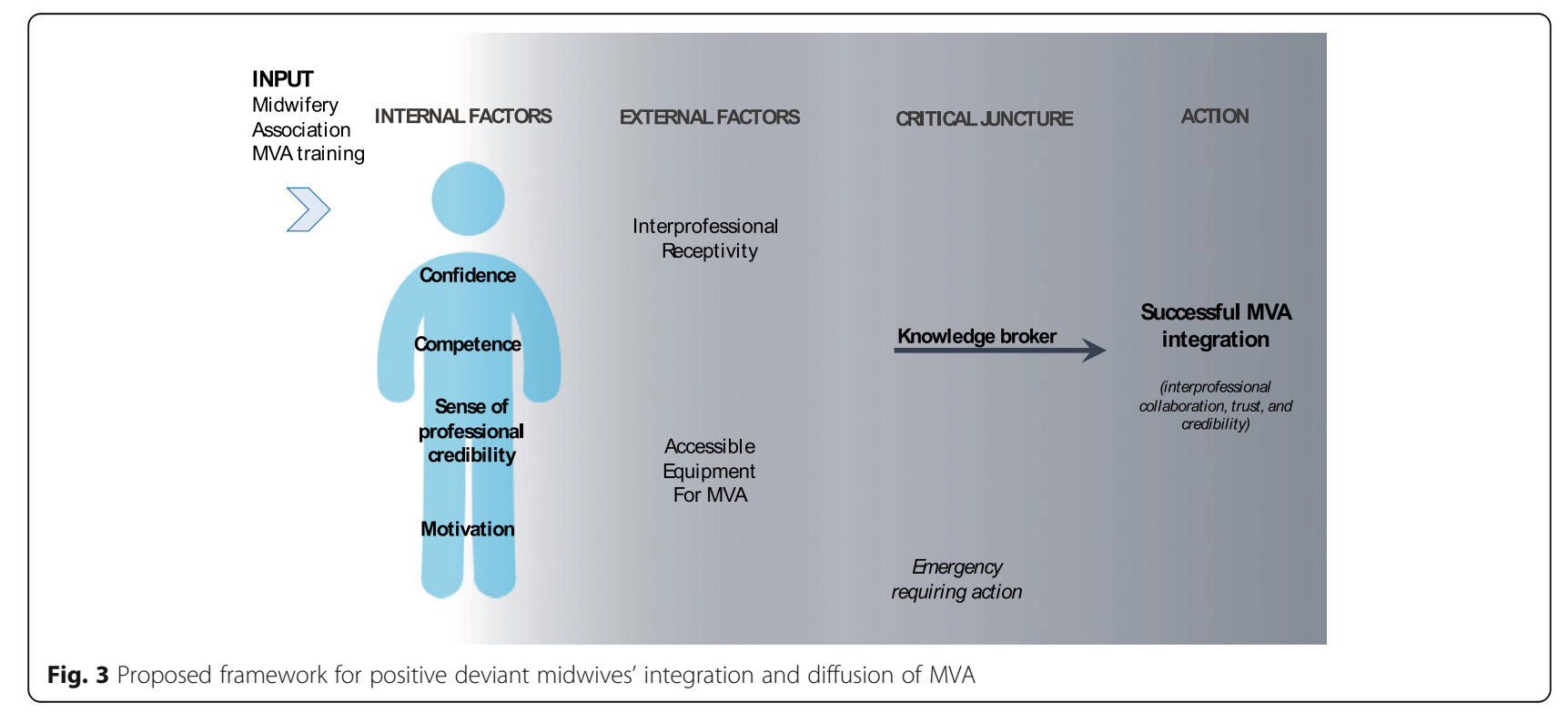


than employing a focus group discussion for validation, results were electronically shared with stakeholders, with dissemination plans occurring at a later date. Another limitation occurred during the data collection period. Frequent deployment of researchers ( $\mathrm{AL}, \mathrm{AN})$ to teach in rural areas caused delays in recruitment for the semi-structured interviews for comparator midwives. During this time lapse, changes in participants' contact numbers resulted in some comparators being no longer reachable. Contactable comparators were easily recruited for the qualitative phase.

\section{Conclusion}

This is the first study to independently examine midwifery integration of MVA in the DRC after training provided by the midwifery association. There is an important link between SCOSAF, the results of our study and the development of the midwifery workforce as it pertains to abortion. Midwifery associations act as a focal point for the profession, ensuring quality midwifery themed training and providing educational support. SCOSAF's training permitted midwives to understand their professional scope and to develop an openness to post abortion care. Future research is needed to explore the link between the impact of midwifery-led training and supports, professional identity and MVA integration. Further, SCOSAF could collaborate with positive deviants to continue to diffuse midwifery-led MVA and grow their capacity in-house to support midwives in abortion care. As knowledge brokers and leaders, positive deviants could properly support midwives who are interested in providing post abortion care, yet who are less confident or competent to practice. Midwifery associations also act as a voice to represent the profession at local and national levels [55]. Midwives' associations must be involved in the policymaking process related to sexual and reproductive health and rights. Yet the extent of their contribution is hindered by a lack of professional recognition or understanding of the roles of midwives in health and political systems. Study results have important implications for SCOSAF as much as it does their membership, allowing them to leverage technical expertise to advocate for relevant and meaningful contributions to governmental and bilateral investments in abortion in the DRC.

\section{Supplementary Information}

The online version contains supplementary material available at https://doi. org/10.1186/s12913-020-05997-7.

Additional file 1.

Additional file 2.

\section{Abbreviations}

MVA: Manual vacuum aspiration; DRC: Democratic Republic of Congo; ICM: International Confederation of Midwives; EmONC: Emergency obstetric and neonatal skills; SCOSAF: Professional Association of Congolese Midwives

\section{Acknowledgments}

We thank Ambrocckha Kabeya, midwife and president of the Société Congolaise de la pratique sage-femme (SCOSAF) for his technical advice and providing in-kind support from SCOSAF. We thank the members of our stakeholder committee, Mrs. Henriette Eke Mbula, country midwife advisor, (UNFPA); Dr. Victor Muela Difunda, vice-president of Société Congolaise de Gynécologie et d'Obstétrique (SCOGO); Dr. Guy Mukumpuri Aniaka, PNSR, Ministry of Health; Dr. Mbumba Kinsanku, CUSO DRC; Dr. Milan Milambu Kaluila PNSR, Ministry of Health; and Jean-Claude Mulunda, IPAS DRC. The authors also thank Dr. Jodie C Gary PhD, RN for her initial counsel and revision of the study protocol with regards to the positive deviant assessment.

\begin{abstract}
Authors' contributions
$\mathrm{KMB}$ conceived the study design with her supervisors SL and AH, coordinated all data collection and was responsible for the analysis. $\mathrm{CH}$ and KM provide content expertise (health systems and reproductive health) to inform the proposal, data collection tools and analysis. AL \& AM contributed to the research design and proposal, research ethics approval in DRC, conducted the data collection, transcription, and validated the data analysis. All authors approved the final manuscript.
\end{abstract}

\section{Funding}

This research was funded in part by the Laurentian University Research Fund. The funders had no role in study design, data collection and analysis, decision to publish, or preparation of the manuscript.

\section{Availability of data and materials}

The datasets generated and/or analysed during the current study are not publicly available because it belongs strictly to the Association of Congolese Midwives (SCOSAF), but are available from the corresponding author on reasonable request.

\section{Ethics approval and consent to participate}

Prior to data collection, we obtained ethics approval from the National Committee of Ethics of the Kinshasa School of Public Health in Kinshasa (\#ESP/CE/088/2019), Democratic Republic of Congo and the Research Ethics Board (\#6017245) at Laurentian University, Canada. Written informed consent was obtained from each participant.

\section{Consent for publication}

Not applicable.

\section{Competing interests}

The authors declare they have no competing interests.

\section{Author details}

${ }^{1}$ School of Midwifery, Faculty of Health Sciences, Laurentian University, 935 Ramsey Lake road, Sudbury, ON, Canada. ${ }^{2}$ School of Nursing, Faculty of Health Sciences, Laurentian University, Sudbury, Canada. ${ }^{3}$ Department of French studies, Laurentian University, Sudbury, Canada. ${ }^{4}$ Jules \& Uldeen Terry Professor Emerita of Maternal and Child Health, Professor Emerita of Epidemiology, Rollins School of Public Health, Emory University, Atlanta, USA. ${ }^{5}$ Département Kimbanguiste de Santé, Société Congolaise de la Pratique Sage-femme, Matadi, République Démocratique du Congo. ${ }^{6}$ Société Congolaise de la Pratique Sage-femme, Institut Supérieur des Sciences Infirmières, Kinshasa, République Démocratique du Congo.

Received: 13 August 2020 Accepted: 4 December 2020

Published online: 10 December 2020

References

1. Chae S, Kayembe PK, Philbin J, Mabika C, Bankole A. The incidence of induced abortion in Kinshasa, Democratic Republic of Congo, 2016. PLoS One. 2017;12:e0184389.

2. Kalonda JC. Sexual violence in Congo-Kinshasa: necessity of decriminalizing abortion. Rev Med Brux. 2012;33:482-6.

3. Onyango MA, Burkhardt G, Scott J, Rouhani S, Haider S, Greiner A, et al. A qualitative analysis of disclosure patterns among women with sexual violence-related pregnancies in eastern Democratic Republic of Congo. PLoS One. 2016;11:e0164631. 
4. Rouhani SA, Scott J, Burkhardt G, Onyango MA, Haider S, Greiner A, et al. A quantitative assessment of termination of sexual violence-related pregnancies in eastern Democratic Republic of Congo. Conflict Health. 2016;10:9.

5. Ministère du Plan et Suivi de la Mise en oeuvre de la Révolution de la Modernité (MPSMRM) et Ministère de la Santé Publique (MSP). Enquête Démographique et de Santé en République Démocratique du Congo 20132014. Rockville: MPSMRM, MSP et ICF International; 2014

6. Owolabi OO, Biddlecom A, Whitehead HS. Health systems' capacity to provide post-abortion care: a multicountry analysis using signal functions. Lancet Glob Health. 2019;7:e110-8.

7. Lince-Deroche N, Kayembe P, Blades N, Mabika C, Williams P, London S. Unintended pregnancy and abortion in Kinshasa, Democratic Republic of Congo: challenges and progress. 2019. https://www.guttmacher.org/report/ unintended-pregnancy-abortion-kinshasa-drc. Accessed 17 Apr 2020.

8. Ishoso DK, Tshefu AK, Delvaux T, Coppieters Y. Extent of induced abortions and occurrence of complications in Kinshasa, Democratic Republic of the Congo. Reprod Health. 2019;16:49.

9. Katuashi DI, Tshefu AK, Coppieters Y. Analysis of induced abortion-related complications in women admitted to the Kinshasa reference general hospital: a tertiary health facility, Democratic Republic of the Congo. Reprod Health. 2018;15. https://doi.org/10.1186/s12978-018-0563-y.

10. Kayembe P, Dikamba N. Évaluation des besoins en soins obstétricaux et néonatals d'urgence dans trois provinces de la République Démocratique du Congo: Rapport d'enquête. Kinshasa: Fonds des Nations Unies pour la population et la Ministère de la Santé Publique République Démocratique du Congo; 2012. http://drc.unfpa.org/sites/default/files/pub-pdf/SONU_ RAPPORT_ENQUETE_FINAL_DU_7_12_2012.pdf.

11. Ntambue AM, Malonga FK, Cowgill KD, Dramaix-Wilmet M, Donnen P. Emergency obstetric and neonatal care availability, use, and quality: a crosssectional study in the city of Lubumbashi, Democratic Republic of the Congo, 2011. BMC Pregnancy Childbirth. 2017;17:40.

12. International Confederation of Midwives (ICM). Midwives' Provision of Abortion-Related Services. https://www.internationalmidwives.org/our-work/ policy-and-practice/icm-position-statements/. Accessed 17 Apr 2020.

13. Fullerton J, Butler MM, Aman C, Reid T, Dowler M. Abortion-related care and the role of the midwife: a global perspective. Int J Women's Health. 2018;10: 751-62.

14. Berer M. Provision of abortion by mid-level providers: international policy, practice and perspectives. Bull World Health Organ. 2009;87:58-63.

15. Ngo TD, Park MH, Free C. Safety and effectiveness of termination services performed by doctors versus midlevel providers: a systematic review and analysis. Int J Women's Health. 2013;5:9-17.

16. Barnard S, Kim C, Park MH, Ngo TD. Doctors or mid-level providers for abortion. In: the Cochrane collaboration, editor. Cochrane database of systematic reviews. Chichester: Wiley; 2015. https://doi.org/10.1002/ 14651858.CD011242.pub2.

17. WHO / Task shifting: global recommendations and guidelines. WHO. http:// www.who.int/workforcealliance/knowledge/resources/taskshifting_ guidelines/en/. Accessed 6 Nov 2018.

18. Starrs AM, Ezeh AC, Barker G, Basu A, Bertrand JT, Blum R, et al. Accelerate progress-sexual and reproductive health and rights for all: report of the Guttmacher-lancet commission. Lancet. 2018:391:2642-92.

19. Ndembi Ndembi AP, Mekuí J, Pheterson G, Alblas M. Midwives and postabortion care in Gabon. Health Hum Rights. 2019;21:145-55.

20. Bogren M, Ndela B, Toko C, Berg M. Midwifery education, regulation and association in the Democratic Republic of Congo (DRC) - current state and challenges. Glob Health Action. 2020;13:1717409.

21. Horton R, Astudillo O. The power of midwifery. Lancet. 2014;384:1075-6.

22. ten Hoope-Bender P, de Bernis L, Campbell J, Downe S, Fauveau V, Fogstad $\mathrm{H}$, et al. Improvement of maternal and newborn health through midwifery. Lancet. 2014:384:1226-35.

23. Bourret $K$, Kabeya A, Perron L, Diallo M. De la théorie à la pratique: approches participatives dans le développement des capacités expériences récentes réussies dans des projets de santé reproductive en Afrique Centrale et l'ouest. Conférence canadienne sur la santé mondiale, Ottawa, Ontario; 2017

24. Étienne T. Rapport d'évaluation programme de formation en soins obstétricaux et néonatals d'urgence. Kinshasa: Société Congolaise de la Pratique Sage-Femme; 2018.
25. Rose AJ, McCullough MB. A practical guide to using the positive deviance method in health services research. Health Serv Res. 2017;52:1207-22.

26. Pascale RT, Sternin J, Sternin M. The power of positive deviance: how unlikely innovators solve the world's toughest problems. Boston: Harvard Business Press; 2010.

27. Babalola S, Awasum D, Quenum-Renaud B. The correlates of safe sex practices among Rwandan youth: a positive deviance approach. Afr J AIDS Res. 2002;1:11-21.

28. Ahrari M, Kuttab A, Khamis S, Farahat AA, Darmstadt GL, Marsh DR, et al. Factors associated with successful pregnancy outcomes in upper Egypt: a positive deviance inquiry. Food Nutr Bull. 2002;23:83-8.

29. Garrett JJ, Barrington C. 'We do the impossible': women overcoming barriers to cervical cancer screening in rural Honduras - a positive deviance analysis. Cult Health Sex. 2013;15:637-51.

30. Kim YM, Heerey M, Kols A. Factors that enable nurse-patient communication in a family planning context: a positive deviance study. Int Nurs Stud. 2008:45:1411-21.

31. Schooley J, Morales L. Learning from the community to improve maternal child health and nutrition: the positive deviance/hearth approach. J Midwifery Women's Health. 2007;52:376-83.

32. Miller S, Billings DL, Clifford B. Midwives and postabortion care: experiences, opinions, and attitudes among participants at the 25th triennial congress of the International Confederation of Midwives. J Midwifery Women's Health. 2002:47:247-55.

33. Colvin CJ, de Heer J, Winterton L, Mellenkamp M, Glenton C, Noyes J, et al. A systematic review of qualitative evidence on barriers and facilitators to the implementation of task-shifting in midwifery services. Midwifery. 2013; 29:1211-21

34. Paul M, Gemzell-Danielsson K, Kiggundu C, Namugenyi R, Klingberg-Allvin $\mathrm{M}$. Barriers and facilitators in the provision of post-abortion care at district level in Central Uganda - a qualitative study focusing on task sharing between physicians and midwives. BMC Health Serv Res. 2014;14. https:// doi.org/10.1186/1472-6963-14-28

35. Creswell JW, Plano Clark VL. Designing and conducting mixed methods research. 3rd ed. Los Angeles: SAGE; 2018.

36. Clark KA, Mitchell EHM, Aboagye PK. Return on investment for essential obstetric care training in Ghana: do trained public sector midwives deliver postabortion care? J Midwifery Women's Health. 2010;55:153-61.

37. Gabrysch S, Civitelli G, Edmond KM, Mathai M, Ali M, Bhutta ZA, et al. New signal functions to measure the ability of health facilities to provide routine and emergency newborn care. PLoS Med. 2012;9. https://doi.org/10.1371/ journal.pmed. 1001340.

38. Ministry of Public Health Democratic Republic of the Congo. Guide de suivi, supervision et évaluation de la formation en Soins Obstétricaux et Néonatals d'Urgence (SONU) Sage-Femme. 2017.

39. Turner KL, Pearson E, George A, Andersen KL. Values clarification workshops to improve abortion knowledge, attitudes and intentions: a pre-post assessment in 12 countries. Reprod Health. 2018;15:40.

40. Turner KL, Chapman P. Transformation des attitudes face à l'avortement : boîte à outils de clarification des valeurs pour une audience internationale; 2009.

41. Rogers EM. Diffusion of innovations. 5th ed. New York: Free Press; 2003.

42. Bradley E. Research in action: using positive deviance to improve quality of health care: Implement Science: IS; 2009. https://doi.org/10.1186/1748-59084-25.

43. Cook S, de Kok B, Odland ML. 'It's a very complicated issue here': understanding the limited and declining use of manual vacuum aspiration for postabortion care in Malawi: a qualitative study. Health Policy Plan. 2017; 32:305-13.

44. Singhal A, Svenkerud PJ. Diffusion of evidence-based interventions or practice-based positive deviations. J Dev Comm. 2018;29:34-44.

45. Berwick DM. Disseminating innovations in health care. JAMA. 2003;289: 1969-75.

46. Glenton C, Sorhaindo AM, Ganatra B, Lewin S. Implementation considerations when expanding health worker roles to include safe abortion care: a five-country case study synthesis. BMC Public Health. 2017; 17:730.

47. WHO | Process of translation and adaptation of instruments. WHO. https:// www.who.int/substance_abuse/research_tools/translation/en/. Accessed 14 Jan 2019. 
48. Gipson JD, Becker D, Mishtal JZ, Norris AH. Conducting collaborative abortion research in international settings. Womens Health Issues. 2011; 21(3):S58-62.

49. Mertens DM. Transformative research and evaluation. New York: Guilford Press; 2009

50. Niezen MGH, Mathijssen JJP. Reframing professional boundaries in healthcare: a systematic review of facilitators and barriers to task reallocation from the domain of medicine to the nursing domain. Health Policy. 2014;117:151-69.

51. Huber D, Curtis C, Irani L, Pappa S, Arrington L. Postabortion care: 20 years of strong evidence on emergency treatment, family planning, and other programming components. Glob Health Sci Prac. 2016;4:481-94.

52. Skuster P. Who can provide abortion care? Considerations for law and policy makers. Kinshasa: IPAS; 2015. http://www.ipas.org/ /media/Files/ PubsManual/WHOPROE15\%20pdf.ashx.

53. Sundaram A, Juarez F, Ahiadeke C, Bankole A, Blades N. The impact of Ghana's R3M programme on the provision of safe abortions and postabortion care. Health Pol Plan. 2015;30:1017-31.

54. Norton TC, Rodriguez DC, Howell C, Reynolds C, Willems S. Maybe we can turn the tide: an explanatory mixed-methods study to understand how knowledge brokers mobilise health evidence in low- and middle-income countries. Evid Policy. 2020. https://doi.org/10.1332/ $174426419 \times 15679622689515$

55. Lopes SC, Titulaer P, Bokosi M, Homer CS, ten Hoope-Bender P. The involvement of midwives associations in policy and planning about the midwifery workforce: a global survey. Midwifery. 2015;31:1096-103.

\section{Publisher's Note}

Springer Nature remains neutral with regard to jurisdictional claims in published maps and institutional affiliations.

Ready to submit your research? Choose BMC and benefit from:

- fast, convenient online submission

- thorough peer review by experienced researchers in your field

- rapid publication on acceptance

- support for research data, including large and complex data types

- gold Open Access which fosters wider collaboration and increased citations

- maximum visibility for your research: over $100 \mathrm{M}$ website views per year

At BMC, research is always in progress.

Learn more biomedcentral.com/submissions 